УДК 621.396.96:004.94

\title{
ИМИТАЦИОННОЕ МОДЕЛИРОВАНИЕ ИЗМЕРИТЕЛЬНОЙ ИНФОРМАЦИИ, ПОЛУЧАЕМОЙ ОТ RFID-МЕТОК В СИСТЕМАХ ПРОСТРАНСТВЕННОЙ ЛОКАЛИЗАЦИИ ОБЬЕКТОВ
}

\author{
ГИМПИЛЕВИЧ Ю. Б., САВОЧКИН Д. А.
}

Севастопольский национальный технический университет,

Украина, Севастополь, 99053, ул. Университетская, 33

\begin{abstract}
Аннотация. В работе рассмотрено моделирование процессов пространственной локализации объектов с использованием систем радиочастотной идентификации (RFID-систем). Разработана методика имитационного моделирования измерительной информации видов proximity, received signal strength (RSS) и read rate (RR), получаемой от пассивных RFID-меток. Методика позволяет проводить предварительное сравнение точности локализации, обеспечиваемой при использовании различных алгоритмов локализации и видов измерительной информации, для произвольных областей локализации. В ходе тестирования методики определено, что относительная погрешность результатов моделирования по сравнению с экспериментальными результатами в среднем составляет $8 \%$ и не превышает $28 \%$.
\end{abstract}

Ключевые слова: радиочастотная идентификация; RFID; имитационное моделирование; локализация; позиционирование; измерительная информация

\section{ВВЕДЕНИЕ}

У современных промышленных и торговых предприятий имеется потребность в системах, позволяющих реализовывать пространственную локализацию различного рода объектов. Для двумерной локализации внутри закрытых помещений часто применяют системы на основе технологии радиочастотной идентификации (RFID-технологии). При использовании RFID-систем на объекты локализации устанавливают специальные RFID-метки, местоположение которых определяется системой. Для вычисления местоположения меток в блоке локализации системы выполняется алгоритм локализации, обрабатывающий измерительную информацию (ИИ), получаемую от меток.

Известно множество различных видов используемой в RFID измерительной информа- ции, среди которых следующие: факт наличия ответа метки (proximity) [1, 2], уровень сигнала от метки RSS (received signal strength) [1, 2], отношение числа принятых ответов метки к общему числу запросов RR (read rate) [3, 4]. Сyществует также значительное число алгоритмов локализации. Одними из наиболее эффективных являются алгоритм пересечений [2], трилатерационный (дальномерный) алгоритм $[2,5]$ и алгоритм $k$ ближайших соседей $(k \mathrm{NN}$ алгоритм) [2, 6]. Кроме того, известны подходы $[7,8]$ по созданию комбинированных алгоритмов, позволяющих объединять результаты нескольких одиночных алгоритмов (например, вышеперечисленных) и обрабатывать ИИ различных видов, полученную при излучении запросных сигналов различной мощности.

Для сравнения эффективности алгоритмов и видов ИИ обычно проводится эксперимен- 